\title{
Environmental Flow Assessment - An Analysis
}

\author{
D. Halwatura and M. M. M. Najim ${ }^{\#}$
}

Environmental Conservation and Management Degree Program, Faculty of Science, University of Kelaniya, Kelaniya, Sri Lanka

${ }^{\#}$ Corresponding Author:

E-mail: mnajim@kln.ac.lk

\begin{abstract}
Natural flow of a river is recognized as vital to sustaining riverine ecosystems. The biotic composition, structure and function of aquatic ecosystems depend largely on the hydrologic regimes; however flows of the world's rivers are increasingly being modified through impoundments. Therefore calculation of the optimum flows for a healthier river is essential but there is no simple figure that can be given for the environmental flow requirements of rivers. Environmental flows refer to water for ecosystems. Ecosystems, however, provide a wide range of valuable services to people. Concept of the environmental flow was initiated not only to discover the river health and to manipulate river flow regimes, but also to get the maximum harvest from free flowing waters. Hence, providing for environmental flows is not exclusively a matter of sustaining ecosystems but also a matter of supporting human well being. As demand for freshwater continues to rise and ways are sought to improve water productivity, decision-making bodies at local, basin and national levels require accurate information on the role of river flows in sustaining a wide range of environmental benefits. For that reason assessment of environmental flows may contribute to setting management rules and monitoring their impact on river health.
\end{abstract}

KEYWORDS: Environment flow assessment, Riverine ecosystems, Water

\section{Introduction}

Rivers have been dreadfully useful to human being in all parts of the earth and provide water to slake the thirst, to fertilize lands and to provide a means of communication, transport and besides destinations for recreation hence water has been described as the single most important resource for human being. They support large biological diversity, support the humans and their activities, and provide several services that no other ecosystem can. Rivers have sustained whole ecosystems supporting biodiversity ever since the world came to existence. There are numerous organisms which are sustained by rivers and some are not only supported by rivers but also are their only habitats. Increase of population density, urbanization, industrialization and agricultural activities cause significant impacts on rivers. 
Korsgaard (2006) stated that the flows of the world's rivers are increasingly being modified through impoundments such as dams and weirs; abstractions for agriculture and urban water supply, drainage return flows, maintenance of flows for navigation and structures for flood control. This does not only threaten the water quantity requirements of rivers but also the quality of the rivers (Postel and Richter, 2003).

Therefore, it is important to find the optimum flow that has to be maintained within a river in order to sustain the riverine ecosystem as well as to get the ceiling benefits from a river. Concept of the environmental flow origins not only to discover the river health and to manipulate river flow regimes, but also to get the maximum harvest of free flowing waters. Dissanayake et al. (2010) stated that environmental flows are a set of discharges of a particular magnitude, frequency and timing that are necessary to ensure a certain range of benefits from a river which are essential to sustain elements of natural aquatic ecosystem and maintain ecosystem (such as fish, flood protection and wild life) is becoming an important trend in water resource management.

\section{Concept of Environmental Flows}

Environmental flow has been given various names, including the environmental flow (regime), instream flow, environmental allocation of ecological flow requirement etc. These are distinct from terms such as compensation flows, which have been set for other purposes such as downstream human use (e.g. irrigation, hydropower) (Acreman and Dunbar, 2004). The natural flow paradigm where the natural flow regime of a river is recognized as vital to sustaining ecosystems, has now been widely accepted. This recognition of flow as a key driver of riverine ecosystems has led to the development of the environmental flows concept (Haas, 2003). Recognition of the escalating hydrological alteration of rivers on a global scale and the resultant environmental degradation has led to the gradual establishment of a field of scientific research termed environmental flow assessment (Arthington et al., 2007). Acreman and Dunbar (2004) stated that international organizations, such as The World Conservation Union (IUCN) are now promoting environmental flow as a key element of integrated water resource management. However, it is increasingly recognized that all elements of flow regime, including floods, medium and low flow are important (Junk et al., 1989; Poff et al., 1997).

Dyson (2003) stated that an environmental flow as the water regime provided within a river, wetland or coastal zone to maintain ecosystems and their benefits where there is competing water uses and where flows are regulated. A distinction may be made between the amount of water needed to maintain an ecosystem in close-to-pristine condition, and that which might eventually be allocated to it, following a process of environmental, social and economic assessment. The latter is referred to as the 'environmental flow', and it will be a flow that maintains the ecosystem in a less than pristine condition. 


\section{Current Status of Environmental Flow Assessment}

Dyson (2003) stated that many ecologists believe that some small portion of flow could be removed without measurable degradation of the ecosystem. How much could be removed in this way is more difficult to assess, with estimates ranging between about $65 \%$ and $95 \%$ of natural flow having to remain, retaining the natural pattern of flow. Once flow manipulations move past this, then river ecologists can advise on patterns and volumes of flows that will result in a range of different river conditions. This information can then be used to choose a condition that allows an acceptable balance between a desired ecosystem condition and other social and economic needs for water. The flows allocated to achieve the chosen condition are the environmental flow.

As demand for freshwater continues to rise and ways are sought to improve water productivity, decision-making bodies at local, basin and national levels require accurate information on the role of river flows in sustaining a wide range of environmental benefits (Acreman and Dunbar, 2004). Smakhtin and Shilpakar (2005) noted that insufficient water was being left in rivers in many parts of the world and urged policy makers to consider the allocation of environmental flows a top priority. The ability of some rivers to provide goods and services has been drastically reduced by the diversion and storage of water and the disposal of pollutants (Mazvimavi et al., 2007). With global problems like climate change, which has resulted in frequent droughts and other climatic anomalies, there is a need to assess the ecosystem (or environmental) and economic water requirements on a river basin scale (Bates et al., 2008).

The protection of the aquatic environment is high on the world water resources agenda but most developing countries, however, still lack the technical and institutional capacity to establish environmental water allocation practices and policies. The existing methods of assessment of environmental water allocations are either complex and resource-intensive (comprehensive holistic approaches) or not tailor made for the specific conditions of a particular country, region or basin. Detailed quantification of natural and present-day hydrology for such assessments in river basins in developing countries is also lacking (Smakhtin and Shilpakar, 2005).

\section{Environmental Flow Assessment in Sri Lanka}

Smakhtin and Weragala (2005) stated that assessment and maintenance of environmental flow requirements of rivers and wetlands have become the accepted concept in several countries in the world and are slowly emerging as such in Sri Lanka. Such assessment methods primarily use daily flow data. Dissanayake et al. (2010) evaluated the environmental flow in Walawe River and it is the only river out of the 103 major rivers in Sri Lanka in which the environmental flow is assessed using range of variability approach (RVA) suggested by Richter et al. (1996). 
Required hydrological information can be generated for the locations where environmental flow assessment is intended, which is the typical case in most of Sri Lanka due to data shortage. Simulating the daily stream flow hydrology of river basins is particularly difficult (compared with monthly modeling, for example), due to the complexity of hydrological processes at this scale and increased data requirements associated with it. The development of environmental flow programs and requirements of other water resources projects will place more focus on detailed daily flow data.

The situation regarding the availability of this type of data is particularly bad in developing countries, including Sri Lanka. On the other hand, countries like Sri Lanka provide an ideal opportunity for establishing a nationwide program of daily data assessment. There are only 52 stations to measure flow in Sri Lanka at present but in the past, there were 142 stations measuring flow (Smakhtin and Weragala, 2005). This is an awful situation in the context of estimation of environmental flows in major rivers of Sri Lanka.

A simple approach to assess environmental flow was suggested by Najim and Mowjood (2009). This approach was based on flow duration curves developed for a diversion site with the help of simulated flows. Based on the flow duration curve developed, the $100 \%$ probable minimum daily flow is considered as the environmental flow that has to be allowed below the intervention point to ensure minimum damage to the biodiversity. As the $100 \%$ probable minimum flow is very small, the minimum flow to be allowed below the intervention point is considered as the $90 \%$ minimum probable flow (Mowjood and Najim, 2011). This approach is used by the Central Environmental Authority of Sri Lanka in providing Environmental Protection Licenses for mini hydropower projects.

\section{Environmental Flow Assessment}

The environmental flow assessment method discussed in this paper is based on Range of Variability Approach (RVA) developed by Richter et al. (1997). In order to calculate RVA targets, Richter et al. (1996) proposed a method that results in the computation of representative, multi-parameter suite of hydrologic characteristics or indicators for assessing hydrologic alteration. This method is referred as the Indicators of Hydrologic Alteration (IHA) method. They proposed 32 hydrological parameters (Table 1), which are defined as a series of biologically relevant hydrologic attributes. These attributes characterize intra-annual variations in water conditions.

An analysis of the intra-annual variations in these attributes are the foundation for comparing hydrologic regimes before versus after a system has been altered by various human activities (drinking water extractions and irrigation diversions) (Smakhtin and Weragala, 2005 and Halwatura, 2011: Unpublished undergraduate theses). As an improvement to this method, in addition to the 32 hydrological 
parameters, four new parameters that reflect the monsoonal patterns of Sri Lanka were included raising the hydrological parameters to 36 (Halwatura, 2011: Unpublished undergraduate theses).

Thirty six ecologically relevant hydrologic parameters (Table 1) for each year in each data series (prior to and after extractions) should be calculated as a set of values for flow of river before irrigation diversions and water extractions and the other set of values for after irrigation diversions and water extractions. Measures of central tendency (means) and dispersion (low and high range limits and standard deviation] are calculated from the annual series for each of the thirty six parameters, which produced 72 inter-annual statistics for each data series (36 measures of central tendency and 36 measures of dispersion) and used to characterize interannual variations. For the future scenarios, 36 IHA values were calculated separately for three sets (flow for minimum rainfall of selected past years, flow for maximum rainfall of selected past years and flow for mean rainfall for selected past years) of calculated flows.

Richter et al. (1997) stated that the fundamental concept of a river management should be in such a way that the annual value of each IHA parameter falls within the range of natural variation for that parameter, as defined by the inter-annual measure of dispersion. Thus the management targets for any given parameter are expressed as a range of acceptable values. The targets may have both upper and lower bounds. The RVA method suggests that, when considering a modified or altered flow regime, all the calculated IHA parameters (36) should be maintained within the natural variability. Richter et al. (1997) recommended that the \pm 1 Standard deviation (SD) value be the default for setting initial RVA targets.

Values at \pm 1 SD from the mean were $[($ mean $-\mathrm{SD})<\mathrm{RVA}<($ mean $+\mathrm{SD})]$ selected as the RVA targets for each of thirty six IHA parameters. For thirty six after extraction IHA parameters, rate of non-attainment (values that fall below the lower limit and above the upper limit of calculated RVA targets) were also calculated. For the future scenarios, rate of non-attainment was calculated by determining whether the calculated three sets (flow for minimum rainfall of past fifty years, flow for maximum rainfall of past fifty years and flow for mean rainfall for past fifty years) of 36 IHA values meet the RVA targets. Group averages for the five IHA groups were calculated for the three sets of IHA values separately.

Richter et al. (1996) stated that thirty two hydrologic characteristics could be used to aid in detection of physical habitat alterations in a lotic system. Sixteen of the hydrologic characteristics focus on the magnitude, duration, timing and frequency of extreme events because of the pervasive influence of extreme forces in ecosystem and geomorphology. The other sixteen parameters measure the central tendency of either the magnitude or rate of change of water condition. 


\section{Table 1: Summary of hydrologic parameters used in the IHAs and their characteristics

\begin{tabular}{lll}
\hline IHA Statistic Group & $\begin{array}{l}\text { Regime } \\
\text { Characteristics }\end{array}$ & Hydrologic Parameters \\
\hline
\end{tabular}

Group 1:

Magnitude of monthly Magnitude Mean value for each calendar month water conditions Timing

Group 2:

Magnitude and duration of annual extreme water conditions
Magnitude Duration
Annual minima 1-day means Annual maxima 1-day means Annual minima 3-day means Annual maxima 3-day means Annual minima 7-day means Annual maxima 7-day means Annual minima 30-day means Annual maxima 30-day means Annual minima 90-day means

Annual maxima 90-day means

Annual mean of $1^{\text {st }}$ inter monsoon*

Annual mean of South West monsoon*

Annual mean of $2^{\text {nd }}$ inter monsoon*

Annual mean of North East monsoon*

Group 3:

Timing of annual

Timing

Julian date of each annual 1 day maximum

extreme water Julian date of each annual 1 day minimum

conditions

Group 4:

Frequency and duration Frequency of high and low pulses Duration

No. of high pulses each year No. of low pulses each year Mean duration of high pulses within each year (day) Mean duration of low pulses within each year (day)

\section{Group 5:}

Rate and frequency of Frequency water condition changes
Means of all positive differences between consecutive daily values Means of all negative differences between consecutive daily values No. of rises No. of falls

\footnotetext{
* Newly added parameters that reflect the monsoonal patterns of Sri Lanka
}

Source: Halwatura (2011): Environmental flow assessment in Attanagalu Oya, unpublished undergraduate thesis. 
To date, not many quantitative studies have addressed the problem of compromises between human water demand and in-stream flow requirements. The major difficulty involved appears from the quantitative assessment of the impacts of water diversions on natural hydrologic regimes. The Range of Variability Approach (RVA) offers a useful approach to quantitatively evaluating the hydrologic impacts in terms of 32 Indicators of Hydrologic Alteration (IHAs) Richter et al. (1996) and Shiau and $\mathrm{Wu}$ (2006).

The RVA aims to provide a comprehensive statistical characterization of ecologically relevant features of a flow regime, where the natural range of hydrological variation is described using 32 different hydrological indices derived from long-term, daily flow records (Tharme, 2003). The RVA is design to bridge a gap between applied river management and current theories of aquatic ecology. Virtually all methods currently in widespread use for determining in-stream flow needs will possibly lead to inadequate protection of ecologically important flow variability, and ultimately to the loss of native riverine biodiversity and ecosystem integrity (Richter et al., 1996).

Colwell (1974) and Richter et al. (1996) stated that the magnitude of the water condition at any given time is a measure of the availability or suitability of habitat and defines such habitat attributes as wetted area or habitat volume, or the position of a water table relative to wetland or riparian plant rooting zones. The timing of occurrence of particular water conditions can determine whether certain life cycle requirements are met or can influence the degree of stress or mortality associated with extreme water conditions such as flood or droughts. The duration of time over which a specific water condition exists may determine whether a particular life cycle phase can be completed or the degree to which stressful effects such as inundation or desiccation can accumulate.

To date, not many quantitative studies have addressed the problem of compromises between human water demand and in-stream flow requirements. Due to alterations of flow regimes in the riverine ecosystems, it might have caused stresses, but are not recorded in the Attanagalu Oya basin (Halwatura, 2011: unpublished undergraduate thesis). The use of the water from rivers for human activities produces alterations in these ecosystems that in many cases are not recognized and have not been evaluated in their true value.

There is growing recognition that functionally intact and biologically complex aquatic ecosystems provide many economically valuable services and long-term benefits to the society (Yount and Niemi, 1990). Impacts of hydrologic alterations on aquatic biota are well documented in the literature (Shiau and $\mathrm{Wu}, 2006$ ) and could be used in environmental flow management.

While IHA approach is originated from the United States, this approach does not consider the monsoonal patterns that play vital role in tropical hydrology. Bates et al. (2008) stated that monsoonal areas are more likely to be affected by more 
intense rainfall events over shorter rainy seasons, exacerbating flooding and erosion in catchments and the wetlands themselves. In monsoonal regions, prolonged dry periods promote terrestrialization of wetlands. Intense rain occurring over fewer days, which implies increased frequency of floods during the monsoon, may also result in reduced groundwater recharge potential.

Expansion of areas under severe water stress will be one of the most pressing environmental problems in South and South-East Asia in the foreseeable future. Indian economy is often called the 'monsoon economy' (Balasubramanian, 2009). It reflects the critical role of the monsoon in tropical agricultural economy. Amarasinghe (2010) stated that monsoonal weather patterns have a major influence on the spatial and temporal variation of water availability within Sri Lanka.

Similarly, other hydrology-based desktop methods developed elsewhere need to be re-calibrated or tested in a different physiographic environment (like the monsoondriven flow regimes of Sri Lanka) before they can be reliably applied. There is, therefore, a need to further develop or modify and test existing methods in specific river basins (Smakhtin and Weragala, 2005). Imbulana et al. (2006) stated that situated close to the equator, the tropical climate of Sri Lanka is characterized by temperatures and monsoonal winds which give rise to rainfall pattern with spatial and temporal variations.

Uneven distribution of the monsoonal precipitation is governed by the total volumes of rain during the monsoons along with the orographic influence of the central mountain region. Some rains occur as a result of convection effects from depressions and local thunderstorms during the transition period between the monsoons. Therefore, in addition to thirty two IHA parameters (Richter et al., 1996), four new IHA parameters that reflect the hydrological alterations due to monsoonal patterns are proposed by Halwatura (2011: unpublished undergraduate thesis).

Smakhtin and Weragala (2005) assessed environmental flow in Walawe River in Sri Lanka. The number of RVA parameters in the modified method used by them is equal to 16 , as opposed to the original 32 . However, this number was reduced, for all practical purposes; to cover the entire range of flows for the construction of the flow duration curve. In their study only 6 parameters have been used. Others have either not been used or not estimated as superfluous.

It is, however, possible to suggest that given the extensive water diversions from Udawalawa, very little water is flowing at environmental flow site 2 (downstream of Udawalawa reservoir) at all times. Therefore, it is unlikely that the RVA lowlimit target is ever met. Halwatura (2011: Unpublished undergraduate theses) stated that mean rate of non-attainment of the Indicators of Hydrologic Alteration (IHA) groups after water withdrawals vary in between $12 \%$ to $80 \%$ in Attanagalu Oya. If the rainfall pattern of the next thirty years shows the maximum rainfall of past fifty years, the mean rate of non-attainment would be $45 \%$. 
The RVA was developed to provide explicit adaptive management guidelines that are responsive to the short term demands of most water management negotiations. The RVA means to enable river managers to define and adopt readily interim management targets before conclusive, long term ecosystem research results are available. The RVA is the response to an urgent need to act in the face of considerable uncertainty. Setting management targets based on a natural range of variation in the thirty two hydrological parameters does not depend upon extensive ecological information, although such information certainly will help select and refine the targets.

An adaptive decision-making process, based upon carefully formulated scientific research and monitoring, holds greatest promise for resolving complex resource management conflicts (Richter et al., 1997). The developed thirty six RVA targets for a particular river can be used as river management targets by the government authorities responsible for irrigation and Water Supply for the future water extractions and diversions in order to get the maximum yield of flowing water in rivers before entering to the Ocean.

\section{Conclusion}

In this paper we have outlined the analysis of environmental flow and illustrated the importance of assessment of environmental flow. Furthermore this provides evidence proving that river flows have been altered and still altering exclusive of maintaining the environmental flows. Hydrology-based methods of environmental flow assessment can provide basic estimates of environmental water requirements at different scales. Implementation of these methods are important as initial steps towards environmental flow assessment in order to acquire the maximum yield of flowing water in rivers while maintaining healthier riverine ecosystem.

\section{References}

Acreman, M. and M. J. Dunbar (2004). "Defining environmental river flow requirements - a review". Hydrology and Earth System Sciences, 8(5): 861-876.

Amarasinghe, U. A. (2010). "Spatial variation of water supply and demand in Sri Lanka". In Jinapala, K., S. de Silva and M. M. M. Aheeyar (Eds.). Proceedings of the National Conference on Water, Food Security and Climate Change, 3: 19-35.

Arthington, A. H., E. Baran, C. A. Brown, P. Dugan, A. S. Halls, M. J. King, C. V. MinteVera, R. E. Tharme and R. L. Welcomme (2007). "Water requirements of floodplain rivers and fisheries: existing decision support tools and pathways for development". Comprehensive Assessment of Water Management in Agriculture Research Report, 1 - 68.

Balasubramanian, T. N. (2009). "Adaptation strategies to sustain food security in India against climate change impact". Proceedings of National Conference on Climate 
Change. JJ College of Engineering and Technology, Trichirapalii, India, August 2008.

Bates, B. C., Z. W. Kundzewicz, S. Wu and J. P. Palutikof (2008). "Climate change and water". Technical Paper of the Intergovernmental Panel on Climate Change (IPCC), IPCC Secretariat, Geneva.

Colwell, R. K. (1974). "Predictability, constancy, and contingency of periodic phenomena". Ecology, 55: 1148-1153.

Dissanayake, P., N. Weragala and V. Smakin (2010). "Environmental flow assessment: recent examples from Sri Lanka". In Evans, A. and K. Jinapala (Eds.). National Conference on Water, Food Security and Climate Change in Sri Lanka, 2: 23-37.

Dyson, M. (2003). "Getting started in environmental flow assessment". In Dyson, M., G. Bergkamp and J. Scanlon (Eds.). Flow: The essentials of the environmental flow, IUCN, Gland, Switzerland, 15-20.

Haas, L. (2003). "Modifying water infrastructure". In Dyson, M., G. Bergkamp and J. Scanlon (Eds.). Flow: The essentials of the environmental flow, IUCN, Gland, Switzerland, 45-55.

Halwatura, D. (2011). "Environmental flow assessment in Attanagalu oya". Unpublished undergraduate thesis, Department of Zoology, University of Kelaniya, Kelaniya, Sri Lanka.

Imbulana, K. A. U. S., N. T. S. Wijesekara and B. R. Neupane (2006). "Sri Lanka National Water Development Report”. MAI and MD, UN-WWAP, UNESCO and University of Moratuwa, Ministry of Agriculture, Irrigation and Mahaweli Development Sri Lanka, Paris and New Delhi, 50-84.

Junk, W. J., P. B. Bayley and R. E. Sparks (1989). "The flood pulse concept in river floodplain systems”. In Dodge, D. P. (Eds.). Proceedings of the International Large River Symposium, Canadian Special Publication of Fisheries and Aquatic Sciences, Ottawa, Canada, 110-127.

Korsgaard, L. (2006). "Environmental flows in integrated water resources management: linking flows, services and values". Institute of Environment and Resources, Technical University of Denmark, Bygningstorvet, Lyngby, 5-8.

Mazvimavi, D., E. Madamombe and H. Makurira (2007). “Assessment of environmental flow requirements for river basin planning in Zimbabwe". Physics and Chemistry of the Earth, 32: 995-1006.

Mowjood, M. I. M. and M. M. M. Najim (2011). "Report on Hydrological study of proposed Mini-hydropower project - Angarakanda", a report submitted to Angarakanda Mini Hydro (Pvt) Ltd. 112/1 High level Road, Pannipitiya.

Najim, M. M. M. and M. I. M. Mowjood (2009). "Hydrological modeling approach to protect biodiversity allowing environmental flows below weirs". Proceedings of the 
Fifteenth Sessions of the Sri Lanka Association for Fisheries and Aquatic Resources, Sri Lanka Association for Fisheries and Aquatic Resources, Sri Lanka.

Poff, N. L., J. D. Allan, M. B. Bain, J. R. Karr, K. L. Prestegaard, D. R. Brian, E. S. Richard and J. C. Stromberg (1997). "The natural flow regime". Bio Science, 47(11): 769-784.

Postel, S. and B. Richter (2003). "Rivers for life. Managing water for people and nature". Island Press, Washington DC, USA.

Richter, B. D., J. V. Baumgartner, J. Powell and D. P. Braun (1996). "A method for assessing hydrologic alteration within ecosystems". Conservation Biology, 10(4): 1163-1174.

Richter, B. D., J. V. Baumgartner, R. Wigington and D. P. Braun (1997). "How much water does a river need?". Freshwater Biology, 37: 231-249.

Shiau, J. and Fu-Chun. Wu (2006). "Compromise programming methodology for determining instream flow under multi-objective water allocation criteria". Journal of the American Water Resources Association, 42(5): 1179-1191.

Smakhtin, V. U. and N. Weragala (2005). "An assessment of hydrology and environmental flows in the Walawe river basin, Sri Lanka". Working Paper 103. International Water Management Institute (IWMI), Colombo, Sri Lanka.

Smakhtin, V. U. and R. L. Shilpakar (2005). "Planning for environmental water allocations an example of hydrology-based assessment in the East Rapti River Nepal”. Research Report 89. International Water Management Institute, Colombo, Sri Lanka.

Tharme, R. E. (2003). “A global perspective on environmental flow assessment: emerging trends in the development and application of environmental flow methodologies for rivers". River research and applications, 19: 397-441.

Yount, J. D. and G. J. Niemi (1990). "Recovery of lotic communities and ecosystem from disturbance - a review of case studies". "Environmental Management", 14: 547-569. 